\title{
Effectiveness of sensory stimulation among children with impaired psychomotor development: a pilot study
}

\author{
DOI: https://doi.org/10.5114/pq.2020.100285
}

\author{
Dorota Wójtowicz', Agnieszka Ptak', Sylwia Świtkowska', Małgorzata Stefańska' \\ Department of Physiotherapy in Neurology and Paediatrics, University School of Physical Education in Wrocław, \\ Wrocław, Poland
}

\section{Abstract}

Introduction. The sense of balance, proprioception, and exteroception are key for healthy psychomotor development and proper functioning of human beings. Any disorders in this area may cause dysfunctions, problems with tactile stimuli perception and muscle tone regulation, as well as lack of motion and body awareness. The aim of the study was to evaluate the effectiveness of sensory integration therapy as a method of supporting psychomotor development in children residing in a long-term care and nursing home.

Methods. The study involved 16 children, randomly divided into 2 equal groups, permanently living in a long-term care and nursing home in Poland. None of the children was diagnosed with autism. The psychomotor development was evaluated with the Sensorimotor History Questionnaire (based on the questionnaire by Balzer-Martin) and the Southern California Postrotary Nystagmus Test by Ayres. The research was performed between October 1, 2016 and June 30, 2017. Each participant underwent the test twice - prior to the therapy and after 8 months of therapy.

Results. There were significant changes in the psychomotor development in the treatment group in areas not correlated with the children's age.

Conclusions. The therapy using the sensory integration approach can potentially support the development of children who are permanent residents of a long-term care and nursing home. The classic formula of the sensory integration therapy (i.e. 1 session per week) may be insufficient in the case of permanently institutionalized children. The study should be expanded and carried out in larger groups of children.

Key words: sensory integration, development, disabled children, behaviour, facility

\section{Introduction}

It is known that sensory integration therapy is considered controversial in the case of autism. It was originally used to support children with learning disabilities and is applied to treat mentally handicapped children with the support of the family environment, but there is still no scientific evidence for its operation.

The added value of this work is the assessment of the possibility to use sensory integration therapy in work with institutionalized children without family support, with a statistically calculated significance of the parameters evaluated during the therapeutic process.

According to the UNICEF Annual Report 2015, disabled children constitute one of the most excluded and marginalized social groups in modern times. In 2017, there were 72,661 children in foster care in Poland, residing in 38,940 institutions and other organizational structures [1]. Foster care institutions comprise orphanages, professional foster families, and specialized care facilities of various profiles, including longterm care and nursing homes. Prolonged stay in foster care institutions causes hospitalism - a disorder resulting in deprivation of emotional and cognitive needs. Among its consequences are abnormalities observed in the area of sensory integration [2]. Disabled children exhibit sensory integration disorders; therefore, attention should be paid to the way they perceive and process various stimuli which impact on their nervous systems [3, 4].
Impaired psychomotor development and sensory integration disorders are related to incorrect processing of sensory stimuli originating from the external environment. It results in ineffective communication between the person and the surroundings, prevents them from functioning properly in everyday life, and hinders the child's development [5]. Sensory integration therapy is increasingly popular, particularly in children with behavioural and developmental disabilities. However, empirical support for sensory-based treatments is limited [5].

The psychomotor development of humans, from birth to full maturity, is a multistep, irreversible process, aimed at achieving successive developmental levels, until the person becomes fully independent and self-reliant. The integration of the sensorimotor system with the visual and auditory perception, as well as the cooperation between the autonomic nervous system and the limbic system, are key elements of the systematic development of human beings. Sensory integration is developed most intensively during the first 72 months of a child's life [6]. The term 'sensory integration' refers to the processing of information from the environment at the brain level in order to integrate and utilize it in everyday life [7]. A defective sensory response system leads to an impairment of psychomotor development and difficulties in everyday life $[8,9]$. Children with sensory integration disorders exhibit problems during walking, grabbing objects, or undertaking sports activities, as well as experience learning difficulties [10]. The vestibular system plays an important role

Correspondence address: Agnieszka Ptak, Department of Physiotherapy in Neurology and Paediatricsy, University School of Physical Education in Wrocław, al. I.J. Paderewskiego 35, 51-612 Wrocław, Poland, e-mail: agnieszka.ptak@awf.wroc.pl 
in sensory integration. A properly functioning vestibular system allows posture control, which is necessary to keep the balance, generate healthy patterns in the area of gross and fine motor skills, as well as provide optimal cognitive conditions which make proper learning possible. The disorders may be related to fine motor skills or abnormal extraocular movements. Smooth eyeball movements and quick focusing are necessary for the proper functioning of the visual organ [11]. Scientifically, sensory integration is based on principles of neuroscience, developmental psychology, occupational therapy, and education. Sensory integration is also based on such key principles as just right challenge, adaptive response, active engagement, and child direct. A combination of all those key principles and scientifically based rules help to understand a child's needs and follow the therapeutic aim. According to Schaaf and Miller [3], all children with developmental disorders have a sensory integration disturbance. The therapy using the sensory integration approach is often referred to as 'scientific playing' and children usually participate in it quite eagerly. The therapy should result in improved functioning of the patient in everyday life, their participation in usual chores, playing, involvement in school activities, etc. [3-6].

Residential care of a child in long-term care and nursing homes satisfies the basic needs of a patient. The scope of operation of such facilities can be expanded and include specialist services, such as teaching or developing functional skills, thus allowing the patient to become independent and self-reliant. This approach constitutes a comprehensive rehabilitation programme, which comprises physical therapy, occupational therapy, speech therapy, psychological assistance, school education, and child's own activity [7].

The aim of the study was to evaluate the effectiveness of therapy using the sensory integration approach as a method of supporting the psychomotor development of children diagnosed with impaired psychomotor development and sensory integration disorders, residing in a long-term care and nursing home.

\section{Subjects and methods}

\section{Participants}

Two numerically equal groups (8 children each) were randomly selected from a group of 16 children who fulfilled the age condition of 2-8 years, developed independent locomotion, and were residents of a long-term care and nursing home in Lower Silesia. All subjects were diagnosed with impaired psychomotor development and sensory integration disorders, none was diagnosed with autism. Student's $t$-test did not show statistically significant differences in the age range (Table 1).

All the 16 children were obligatorily subjected to therapeutic and didactic classes, which included general development exercises, manual exercises, and social skills trainings. Additionally, 8 children from the treatment group participated in sensory integration therapy. In accordance with the prin-

Table 1. Group characteristics concerning age

\begin{tabular}{|l|c|c|c|c|c|}
\hline \multirow{2}{*}{ Parameter } & \multicolumn{2}{|c|}{ Examined group } & \multicolumn{2}{|c|}{ Control group } & $\begin{array}{c}\text { Examined } \\
\text { vs. control }\end{array}$ \\
\cline { 2 - 6 } & Mean & $S D$ & Mean & $S D$ & $p$ \\
\hline Age (years) & 3.69 & 1.33 & 5.04 & 1.75 & $0.4815^{\star}$ \\
\hline
\end{tabular}

ciples of the sensory integration method, the sessions were carried out once per week over the period of 8 months and lasted approximately 45 minutes each. The duration of sessions was adjusted to the capabilities of the participant at a given time, and the therapy, in accordance with its principles, was adapted in order to address the individual deficits of each child [7-9]. The premise of the therapy was to improve modulation and differentiation within the base systems, visual perception, visual-motor coordination, static and dynamic balance, and praxis. Therapy was always conducted by the same therapist in the same place. The leading therapist was obliged to graduate the difficulties of the therapeutic tasks and adjust the therapy to the current capabilities of the patient. An agreement should have been reached with the child, who should have experienced joy while participating in the therapy, but also should have felt that at the same time, they succeeded at overcoming their limits and achieving goals. Otherwise, the set objective of the therapy could not have been attained [7, 9-12].

The children's legal guardians and the director of the institution were informed on the possibility to withdraw at any time and on the data confidentiality.

\section{Research methods}

In order to evaluate the status of all participants of the research project and monitor the therapy results, the Sensorimotor History Questionnaire according to Balzer-Martin and the Southern California Postrotary Nystagmus Test according to Ayers were used [13]. The children underwent the tests prior to the beginning of therapy and subsequently after 8 months of therapy.

The Postrotary Nystagmus Test is carried out with a rotary board. The child sits on the board and the therapist rotates it 10 times (one rotation should last 2 seconds), thus stimulating the vestibular system. The board is then stopped and the duration of nystagmus is measured. Subsequently, the same procedure is carried out again, in the opposite direction. The nystagmus duration is read from the Postrotary Nystagmus Test chart.

The Sensorimotor History Questionnaire consists of sections which are used to evaluate the following areas: touch, movement and balance, coordination, muscle tone, hearing, vision, smell, and behaviour. All characteristics are assessed with points. The higher the score, the more extensive the sensory integration disorder. The diagnosis is based on the results, determining whether the child qualifies for sensory integration therapy or not. The therapist uses the diagnosis to ascertain the individual status of each patient and design the therapy accordingly. While filling in the questionnaire, the opinion of the child's guardians and the persons who spend time with them on a daily basis (teachers, counsellors, speech therapists, psychologists, etc.) may prove helpful [6]. The Postrotary Nystagmus Test belongs to a large group of 18 Southern California Sensory Integration Tests, created by Ayres and applicable since 1980 [6]. This test quantifies the functioning and dysfunctions of the vestibular and proprioceptive system, which controls body posture, muscle tone, and balance by continuously integrating afferent (inward) and efferent (outward) information [9].

\section{Statistical analysis}

The Statistica 13.1 software was used for statistical analysis. The Mann-Whitney $U$ test was applied to see if there was a statistically significant difference between the study groups 
at the beginning of therapy. The Wilcoxon test checked whether there were statistically significant differences in the groups between the measurements. Friedman's ANOVA test verified whether age significantly affected the test parameters in examinations 1 and 2 . In the case of showing significant differences, a post-hoc test was used.

\section{Ethical approval}

The research related to human use has complied with all the relevant national regulations and institutional policies, has followed the tenets of the Declaration of Helsinki, and has been approved by the Senate Committee on Ethics in Scientific Research at the University School of Physical Education in Wrocław.

\section{Informed consent}

Informed consent to the children's participation in the study was given by the director of the facility and the children's legal guardians.

\section{Results}

\section{Postrotary Nystagmus Test}

During the first Postrotary Nystagmus Test, carried out prior to the beginning of therapy, not all of the children, i.e. 7 children in the treatment group and 6 children in the control group, completed the task. The subjects were examined in a siting position with open eyes and head in a vertical position. After 8 months, all of the participants from both groups were able to complete the full test (Table 2).

As per the Postrotary Nystagmus Test chart according to Ayres, the results, i.e. the nystagmus duration measured in seconds, are divided into 3 categories:

- normal, i.e. values between -0.5 and +0.5 ;

- below -0.5 , indicating hyposensitivity of the vestibular system;

- above +0.5 , indicating hypersensitivity of the vestibular system.

In terms of the Postrotary Nystagmus Test, as concluded from the results presented above, a statistically significant change $(p>0.05)$ was observed only in those children who did not participate in the therapy using the sensory integration approach. In this group, the mean results changed significantly, indicating hyposensitivity of the vestibular system in the first test and hypersensitivity in the second test. Meanwhile, in the treatment group, the mean results changed from being indicative of hypersensitivity of the vestibular system in the first test to remaining within the norm in the second test. This speaks for using sensory integration therapy.

\section{Sensorimotor History Questionnaire}

Table 3 illustrates the scores achieved by the children from the treatment group prior to the beginning of therapy employing the sensory integration method and after 8 months of therapy. The area characterized by the largest deficit was hearing. The area characterized by the smallest deficit was touch. After 8 months of therapy carried out in accordance with the sensory integration method, in the treatment group, the deficit in all areas decreased as compared with the results obtained prior to therapy. It indicates that the participants made a certain progress. The worst results were observed in the area of movement and balance, as well as hearing, whereas the fields of touch and vision saw the most considerable improvement. In the control group, the most serious issues were observed in the areas of touch and vision. During the 8 months of therapy, the control group also underwent changes, although not taking part in the sessions carried out with the sensory integration method. The participants from that group made the most considerable progress in the areas of touch and movement and balance.

The statistical analysis using the Mann-Whitney $U$ test revealed that parameters did not show statistically significant differences between the groups in the first examination in the assessed areas except for touch and vision (Table 4); however, there were differences between the first and second examination in both groups. The analysis of the results confirms that the therapy employing the sensory integration approach produced a statistically significant change in the treatment group in the areas of coordination, muscle tone, hearing, and behaviour. It should be noted that the investigated changes did not correlate statistically with the age of the children in the study group. In the control group, the change that occurred in terms of movement and balance correlated with age. Overall, a statistically significant improvement in the muscle tone was observed in the participants from both groups, without significant differences with age (Table 4).

\section{Discussion}

Schoen et al. [14] describe the observation of a healthyborn child who received occupational therapy with sensory integration intervention within 10 months. The boy showed improvement in skills in all 6 'goals' assessed during the 10-month sensory integration therapy. Data in own research were collected in an interval of 8 months in a group of handicapped abandoned children. Statistical analysis showed statistically significant changes that did not correlate with age

Table 2. Comparison of the Postrotary Nystagmus Test results prior to sensory integration therapy and after 8 months (Wilcoxon matched-pairs test)

\begin{tabular}{|c|c|c|c|c|}
\hline \multicolumn{5}{|l|}{ Examined group - nystagmus (s) } \\
\hline Test & $n$ & Mean & Median & $p$ \\
\hline Prior to therapy & 7 & 0.67 & 0.40 & \multirow{2}{*}{0.0629} \\
\hline After 8 months of sensory integration therapy & 8 & 0.00 & 0.60 & \\
\hline \multicolumn{5}{|l|}{ Control croup - nystagmus (s) } \\
\hline Test & $n$ & Mean & Median & $p$ \\
\hline Prior to therapy & 6 & -0.27 & -0.45 & \multirow{2}{*}{$0.04311^{*}$} \\
\hline After 8 months without sensory integration therapy & 8 & 0.95 & 1.10 & \\
\hline
\end{tabular}

${ }^{*} p<0.05$, Wilcoxon test 
Table 3. Comparison of the Sensorimotor History Questionnaire scores in the treatment and control groups during the first test and after 8 months

\begin{tabular}{|c|c|c|c|c|c|}
\hline \multirow{2}{*}{ Group } & \multirow{2}{*}{ Domain } & \multicolumn{2}{|c|}{ Examination 1} & \multicolumn{2}{|c|}{ Examination 2} \\
\hline & & Mean & $S D$ & Mean & $S D$ \\
\hline \multirow{8}{*}{ Examined group } & Touch & 0.88 & 0.83 & 0.38 & 0.74 \\
\hline & Movement and balance & 2.25 & 1.16 & 1.50 & 0.76 \\
\hline & Coordination & 1.75 & 1.49 & 1.13 & 1.13 \\
\hline & Muscle tone & 2.25 & 1.16 & 1.25 & 0.89 \\
\hline & Hearing & 3.50 & 2.14 & 1.38 & 1.41 \\
\hline & Vision & 1.75 & 2.05 & 0.25 & 0.46 \\
\hline & Smell & 1.88 & 0.35 & 1.13 & 0.83 \\
\hline & Behaviour & 2.13 & 1.64 & 1.25 & 1.58 \\
\hline \multirow{8}{*}{ Control group } & Touch & 4.13 & 2.10 & 2.50 & 2.33 \\
\hline & Movement and balance & 2.75 & 0.71 & 1.75 & 0.71 \\
\hline & Coordination & 3.13 & 1.13 & 2.50 & 1.07 \\
\hline & Muscle tone & 2.75 & 1.28 & 2.13 & 1.13 \\
\hline & Hearing & 3.00 & 1.60 & 2.50 & 1.20 \\
\hline & Vision & 4.25 & 1.28 & 3.13 & 1.36 \\
\hline & Smell & 2.13 & 0.35 & 2.00 & 0.00 \\
\hline & Behaviour & 2.88 & 0.83 & 2.50 & 0.53 \\
\hline
\end{tabular}

Table 4. Comparison of the Sensorimotor History Questionnaire scores for children from the treatment group and the control group in the first examination and after 8 months

\begin{tabular}{|c|c|c|c|c|c|c|c|c|}
\hline \multirow{2}{*}{ Domain } & 1 vs. $2 \mathrm{E}$ & 1 vs. $2 \mathrm{C}$ & E1 vs. C1 & E2 vs. C2 & \multirow{2}{*}{ Age vs. E1 } & \multirow{2}{*}{ Age vs. E2 } & \multirow{2}{*}{ Age vs. C1 } & \multirow{2}{*}{ Age vs. C2 } \\
\hline & $p(\mathrm{~W})$ & $p(W)$ & $p(\mathrm{MW})$ & $p(\mathrm{MW})$ & & & & \\
\hline Touch & 0.0679 & $0.0117^{*}$ & $0.0028^{* *}$ & 0.0520 & 8.88 & $11.13^{\star \star *}$ & 1.63 & 6.94 \\
\hline Movement and balance & 0.0679 & $0.0277^{*}$ & 0.4309 & 0.4948 & 2.81 & 5.63 & 5.56 & $9.81^{* * *}$ \\
\hline Coordination & $0.0431^{*}$ & 0.1088 & 0.0742 & $0.0406^{\star *}$ & 5.13 & 8.00 & 3.63 & 5.81 \\
\hline Muscle tone & $0.0277^{*}$ & $0.0431^{*}$ & 0.4623 & 0.1278 & 2.63 & 7.00 & 5.69 & 7.81 \\
\hline Hearing & $0.0180^{*}$ & 0.1088 & 0.7527 & 0.1415 & 0.06 & 6.19 & 4.50 & 6.25 \\
\hline Vision & 0.0679 & $0.0431^{*}$ & $0.0274^{\star *}$ & $0.0009^{\star *}$ & 5.63 & $11.06^{\star \star *}$ & 0.50 & 4.38 \\
\hline Smell & 0.0679 & NS & 0.4623 & $0.0406^{\star *}$ & 3.75 & 6.75 & 8.56 & $9.06^{\star \star *}$ \\
\hline Behaviour & $0.0180^{*}$ & 0.1088 & 0.2076 & 0.1036 & 3.19 & 7.81 & 4.81 & 6.44 \\
\hline
\end{tabular}

E - examination group, C - control group, E1 - examination group first examination, C1 - control group first examination,

E2 - examination group second examination, C2 - control group second examination

W - Wilcoxon test, MW - Mann-Whitney $U$ test, NS - not significant

${ }^{*} p \leq 0.05$, Wilcoxon test, ${ }^{* *} p \leq 0.05$, Mann-Whitney $U$ test, ${ }^{* * *}$ significant value, post-hoc test for Friedman's ANOVA

in 4 - coordination, muscle tone, hearing, and behaviour of the 8 assessed parameters in the study group. In the control group, changes in the 4 observed traits were also reported, however 2 of them - touch and vision - should be excluded from consideration owing to statistically significant differences between the groups in the first study. The parameter defined as motion and balance correlated with age in the control group. The only parameter that showed a statistically significant change in the control group without other dependencies was muscle tone. Statistically significant changes were also noted in the Postrotary Nystagmus Test in the control tibular system, which is crucial from the perspective of body balance, posture control, movement capabilities, and, consequently, functional capabilities and involvement in everyday activities. The results of own research obtained in the Sensorimotor History Questionnaire confirm that after 8 months of therapy, changes occurred in the parameters referred to as movement and balance, hearing, and behaviour, which are related to the functioning of the vestibular system, evaluated with the Postrotary Nystagmus Test. The research conducted by Mulligan [11] confirms that using the aforementioned test as a reliable diagnostic tool is appropriate. 
Ermer and Dunn [15] demonstrated that the area which was most susceptible to modification was behaviour. This fact is consistent with the results achieved during own research by the treatment group participants, where a statistically significant change was observed in the area of behaviour. In the mentioned article, the authors determined a change in all sections of the Sensorimotor History Questionnaire; this was not achieved during the assessment of the treatment group as part of own research. It should be emphasized that the treatment group studied by the quoted authors consisted solely of healthy children who lived permanently in their family homes. Those conditions were different from the conditions of the group studied during own research.

Schoen et al. [16] evaluated 179 children and showed a correlation between sensory processing impairment and behaviour. A positive influence of the therapy on the areas of emotions, behaviour, and motor skills were observed. The authors suggest that a short but intensive therapy programme is effective in the case of children with sensory integration disorders. The frequency of sessions recommended in the aforementioned studies ranges from 3 to 5 units of therapy per week. In own research, this frequency was considerably lower (1 session per week); it suggests that therapy carried out once per week, in accordance with the sensory integration approach, was not sufficient to exert a positive impact on all of the evaluated areas. It should be verified whether the innovative approach proposed by the authors, i.e. the introduction of a short and intensive therapy model, could improve the effectiveness in the areas of children's development and functioning.

Wilbarger et al. [17] assessed children under long-term institutional care. The results indicate that early institutionalization causes sensory integration disorders. The authors state that a monotonous lifestyle revolving around routine contributes to developing sensory processing impairments. Insufficient quantity and variety of stimuli and failure to meet basic emotional needs result in hospitalism. Characteristic rocking back and forth, auto-aggressive behaviours, interests which are not age-appropriate, avoiding the use of senses, or self-mutilation are the elements of 'auto-stimulation,' which provides the child with monotonous sensory stimuli and, consequently, impairs the sensory processing. The aforementioned studies are consistent with own research, where all elements evaluated in both groups with the Sensorimotor History Questionnaire were defined as requiring therapy.

Schoen et al. [14] also point out the crucial role of family as the basic organizational unit for the children. Furthermore, Bennett and Peterson [18] emphasize the immense importance of family as the unit which supports the child's development with the sensory integration method. In their research, they point out the insufficient number of hours of therapy received by children with impaired psychomotor development and recommend that families be included in the therapeutic process. However, it can be denied that there are still thousands of children staying in care and treatment institutions or orphanages in Eastern Europe whose quality of life depends on therapy $[19,20]$. This does, however, demonstrate that there is a problem, i.e. the existence of sensory integration disorders in hospitalized children, and that the therapy sessions should be carried out more frequently in order to improve all areas evaluated with the Sensorimotor History Questionnaire.

\section{Conclusions}

Although there is not much scientifically grounded evidence for its effectiveness, the popularity of sensory integration therapy is increasing all over the world and its use is becoming common in many disease entities. Researchers underline the essence of family cooperation as an element supporting the therapeutic process and ask if institutionalized children, lacking additional family stimulation, will also benefit from such therapy. Sensory integration disturbance can also be associated with computerization; so, it is important to sensitize caregivers to this subject. This publication makes us think how to modify sensory integration therapy in order to gain benefits in all assessed fields.

\section{Disclosure statement}

No author has any financial interest or received any financial benefit from this research.

\section{Conflict of interest}

The authors state no conflict of interest.

\section{References}

1. Statistics Poland. 2017. Available from: http://stat.gov.pl/.

2. Roeber BJ, Tober CL, Bolt DM, Pollak SD. Gross motor development in children adopted from orphanage settings. Dev Med Child Neurol. 2012;54(6):527-531; doi: 10.1111/j.1469-8749.2012.04257.x.

3. Schaaf RC, Miller LJ. Occupational therapy using a sensory integrative approach for children with developmental disabilities. Ment Retard Dev Disabil Res Rev. 2005;11(2): 143-148; doi: 10.1002/mrdd.20067.

4. Gieysztor E, Kurzaj P, Choińska AM, Kowal M, Pecuch A, Borowicz W, et al. Perception of sensory impressions in children from music classes and their peers from general classes in Poland - a comparison. Physiother Quart. 2019;27(4):26-30; doi: 10.5114/pq.2019.87736.

5. Kloze A, Stępowska J. Motor development of a child in the first three months of life. Adv Rehabil. 2019;33(1):4348; doi: 10.5114/areh.2019.84188.

6. Radzimińska A, Strojek K, Kaźmierczak U, Weber-Rajek M, Srokowski G, Bułatowicz I, et al. Assessment of the behavior of a child with sensory integration disorder [in Polish]. J Educ Health Sport. 2015;5(11):685-697; doi: 10.5281/zenodo.41447.

7. Barton EE, Reichow B, Schnitz A, Smith IC, Sherlock D. A systematic review of sensory-based treatments for children with disabilities. Res Dev Disabil. 2015;37:6480; doi: 10.1016/j.ridd.2014.11.006.

8. Olson LJ, Moulton HJ. Occupational therapists' reported experiences using weighted vests with children with specific developmental disorders. Occup Ther Int. 2004;11(1): 52-66; doi: 10.1002/oti.197.

9. Pyda-Dulewicz A, Pepaś R, Konopka W. The use of sensory integration therapy in the rehabilitation of balance disorders in children [in Polish]. Otorynolaryngologia. 2014;13(4):186-190.

10. Mailloux Z, Mulligan S, Roley SS, Blanche E, Cermak S, Coleman GG, et al. Verification and clarification of patterns of sensory integrative dysfunction. Am J Occup Ther. 2011;65(2):143-151; doi: 10.5014/ajot.2011.000752.

11. Mulligan S. Validity of the Postrotary Nystagmus Test for measuring vestibular function. OTJR: Occup Part Heal. 2011;31(2):97-104; doi: 10.3928/15394492-20100823-02.

12. McLeod BD, Weisz JR. The therapy process observational coding system for child psychotherapy strategies 
scale. J Clin Child Adolesc Psychol. 2010;39(3):436443; doi: 10.1080/15374411003691750.

13. Polatajko HJ. The Southern California Postrotary Nystagmus Test: a validity study. Can J Occup Ther. 1983;50(4): 119-123; doi: 10.1177/000841748305000404.

14. Schoen SA, Miller LJ, Sullivan J. The development and psychometric properties of the Sensory Processing Scale Inventory: a report measure of sensory modulation. J Intellect Dev Disabil. 2017;42(1):12-21; doi: 10.3109/ 13668250.2016.1195490.

15. Ermer J, Dunn W. The sensory profile: a discriminant analysis of children with and without disabilities. Am J Occup Ther. 1998;52(4):283-290; doi: 10.5014/ajot.52. 4.283.

16. Schoen SA, Miller LJ, Flanagan J. A retrospective prepost treatment study of occupational therapy intervention for children with sensory processing challenges. Open J Occup Ther. 2018;6(1):4; doi: 10.15453/21686408.1367.

17. Wilbarger J, Gunnar M, Schneider M, Pollak S. Sensory processing in internationally adopted, post-institutionalized children. J Child Psychol Psychiatry. 2010;51(10): 1105-1114; doi: 10.1111/j.1469-7610.2010.02255.x.

18. Bennett JW, Peterson CQ. The touch inventory for elementary-school-aged children: test-retest reliability and mother-child correlations. Am J Occup Ther. 1995;49(8): 795-801; doi: 10.5014/ajot.49.8.795.

19. The WHOQOL Group. The World Health Organization quality of life assessment (WHOQOL): position paper from the World Health Organization. Soc Sci Med. 1995; 41(10):1403-1409; doi: 10.1016/0277-9536(95)00112-k.

20. Schaaf RC, Miller LJ, Seawell D, O'Keefe S. Children with disturbances in sensory processing: a pilot study examining the role of the parasympathetic nervous system. Am J Occup Ther. 2003;57(4):442-449; doi: 10.5014/ ajot.57.4.442. 